BARBOSA, F.S.S.P. et al. Marketing na pecuária de corte. PUBVET, Londrina, V. 7, N. 19, Ed. 242, Art. 1602, Outubro, 2013.

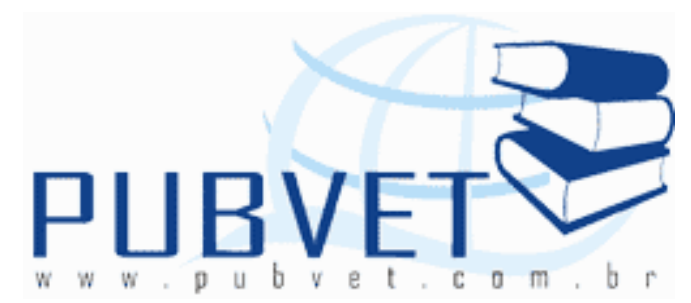

PUBVET, Publicações em Medicina Veterinária e Zootecnia.

\title{
Marketing na pecuária de corte
}

Felipe Silva S. de P. Barbosa ${ }^{1}$, Rafael Alves da Costa Ferro ${ }^{2}$, Miliane Alves da Costa $^{3}$, Klayto José Gonçalves dos Santos², Diogo Alves da Costa Ferro $^{2}$, Luciano Schneider da Silva²

1Zootecnista pela UEG-UnU de São Luís de Montes Belos

2 Docentes do Curso de Zootecnia da UEG-UnU de São Luís de Montes Belos

3 Graduanda em Zootecnia pela UEG-UnU de São Luís de Montes Belos

\section{Resumo}

A pecuária de corte no Brasil é hoje um dos ramos da agropecuária de grande expressão na economia. O Brasil possui um rebanho bovino de aproximadamente 200 milhões de cabeças. Isto faz com que ocorra uma necessidade de um marketing bem planejado para que se tenha o maior domínio possível do mercado mundial da carne. Na pecuária de elite, em um nível de acesso menor, também faz-se uso do marketing, é esse o responsável por divulgar os avanços no melhoramento genético, posteriormente aplicado ao rebanho comercial melhorando sua qualidade. É conhecendo as formas e as etapas do marketing que se pode aplicá-lo de forma eficiente, sendo esse dividido em dois, o marketing estratégico (a longo prazo) e o operacional (curto prazo). Essas estratégias possuem quatro fundamentos, análise, adaptação, ativação e avaliação. Conhecendo o marketing brasileiro é preciso avaliar o mercado do país que é bastante promissor devido a uma melhora na renda dos brasileiros. Isto mostra que a 
BARBOSA, F.S.S.P. et al. Marketing na pecuária de corte. PUBVET, Londrina, V. 7, N. 19, Ed. 242, Art. 1602, Outubro, 2013.

demanda mundial por carne bovina virá de países em desenvolvimento, onde o Brasil é um ótimo exemplo, por produzir carne de altíssima qualidade e vender pelo mesmo preço que a carne mais cara dos EUA. O produto de luxo está globalizado e o Brasil tem nichos e segmentos de mercado que pagam tão bem quanto os melhores dos EUA e Europa. Um importante exemplo a seguir nesta área é a Austrália, um país que investiu em marketing e hoje, possuiu uma marca forte no mercado da carne. Objetivouseos tipos de marketing existentes, bem como suas etapas e características, definir os segmentos do marketing dentro do agronegócio, e analisar o mercado da pecuária de corte no Brasil e no mundo. Observou-se a necessidade do marketing para se adequar ao mercado mundial do segmento, e também a condição do Brasil dentro deste segmento, pecuária de corte, também foi observada a importância do marketing na pecuária de elite, que tem a função de divulgar um bom produto posteriormente aplicado ao rebanho comercial na forma de genética de qualidade.

Palavras-chave: Austrália, estratégico, mercado, operacional

\section{Marketing in beef cattle}

\section{Abstract}

Brazil has a cattle herd of approximately 200 million head's. This quote causes a need for a well planned marketing in order to have the largest possible domain of the world market for meat. In livestock elite in a lower level of access also makes use of marketing, this is responsible for disseminating advances in breeding, later applied to the commercial herd, improving their quality. It is knowing the forms and stages of marketing that you can apply it efficiently, and this divided into two, strategic marketing (long term) and operational (short term). These strategies have four fundamentals, analysis, adaptation, activation and evaluation. Understanding marketing is necessary to evaluate the Brazilian market in the country, is very promising due to an improvement in income Brazilians. 
BARBOSA, F.S.S.P. et al. Marketing na pecuária de corte. PUBVET, Londrina, V. 7, N. 19, Ed. 242, Art. 1602, Outubro, 2013.

This shows that the global demand for beef will come from developing countries, where Brazil is a great example, by producing high quality meat and sell the same price as the meat more expensive in the U.S.. The luxury product is globalized and Brazil has niches and market segments that pay as well as the best U.S. and Europe. An important example to follow in this area is Australia, a country that has invested in marketing and today possesses a strong brand in the meat market. The objective of this literature is describe the types of existing marketing and its stages and characteristics define the segments of marketing in agribusiness, and analyze the market for beef cattle production in Brazil and worldwide. There is a need for marketing to suit the global market segment, and also the condition of Brazil within this segment, beef cattle, was also observed the importance of marketing in livestock elite, whose function is to disseminate good product was then applied to the commercial herd in the form of genetic quality.

Keywords: Australia, market, operational, strategic.

\section{INTRODUÇÃO}

O Brasil possui mais animais da espécie bovina em seu território do que habitantes. Os dados também revelam um crescimento no rebanho bovino de 5,51\% entre os anos de 2002 e 2003, apontando o número de 195,5 milhões.

Exporta atualmente, carne bovina para mais de 100 países, o que fortalece sua posição como o maior exportador mundial de carne. Um dos principais motivos para a carne brasileira ser consumida no mundo inteiro é o fato de quase a totalidade dos rebanhos serem criados livres nas pastagens e não confinados (RANK BRASIL, 2008).

Por isso há necessidade de um bom estudo em marketing, para que assim como ocorre na Austrália, com a Carne Australiana, crie-se uma marca de carne brasileira, valorizando ainda mais seu valor de mercado.

Conhecer o marketing e saber como usa-lo é muito importante dentro de qualquer nicho de mercado. O marketing envolve todo o planejamento de 
BARBOSA, F.S.S.P. et al. Marketing na pecuária de corte. PUBVET, Londrina, V. 7, N. 19, Ed. 242, Art. 1602, Outubro, 2013.

comercialização de mercado desde a escolha do que produzir até a sua chegada ao consumidor. É por isso que a propaganda é um dos elementos principais desse processo mercadológico, pois é ela quem estreita o laço entre empresa e consumidor.

Mas, para fazer a propaganda é preciso conhecer o produto, o consumidor, o mercado e tudo que está contido nele.Avaliar as preferências do consumidor, adequar a qualidade ao preço, e utilizar meios para que o consumidor conheça o produto, são os requisitos básicos da mercadologia.

Na pecuária de corte não é diferente, países estão investindo cada vez mais na propaganda de seus cortes, investindo em pesquisas de mercado e acirrando a competição entre si. Meios como internet, feiras, televisão e revistas já estão sobre domínio de empresas do ramo em diversos países, mas também é preciso maior incentivo estatal.

$\mathrm{Na}$ pecuária de elite, mesmo que de forma menor, há uma intensa utilização do marketing. Criadores investem na imagem dos animais, da propriedade e na própria imagem, aliam-se a produtores com nomes de maior referência para fazer com que o seu produto esteja dentro dos interesses de bons compradores.

Objetivou-se demonstrar os princípios básicos do marketing bem como, elucidar a sua importância dentro da pecuária mundial e sua utilização na área da criação de Nelores de Elite.

\section{REVISÃO DA LITERATURA}

\subsection{Definição de Marketing}

O conceito mais tradicional de marketing, de acordo com aAMERICAN MARKETING ASSOCIATION (1960), é o desempenho das atividades empresariais que dirigem o fluxo de mercadorias e serviços do produtor para o consumidor final (ARAÚJO, 2010) . 
BARBOSA, F.S.S.P. et al. Marketing na pecuária de corte. PUBVET, Londrina, V. 7, N. 19, Ed. 242, Art. 1602, Outubro, 2013.

Segundo ARAÚjO (2010), essa concepção é incompleta, sobretudo por que parte da ideia de fluxo no sentido de produção de bens ou serviços para o consumidor, quando na verdade seria que o fluxo parte do consumidor em seguida para a produção.

Para SILVA\& BATALHA (2010), marketing é definido como, a atividade humana ou processo social, orientados para a satisfação de desejos ou necessidades de indivíduos ou organizações através dos processos de troca.

\subsection{Tipos de Marketing}

Existem dois tipos de marketing: operacional e estratégico (ARAUJO, 2010).

Marketing estratégico são as formas de atuação da empresa, ou caminhos seguidos, voltados constantemente para a análise dos seus mercados de referência ou publico alvo, de modo a identificar produtos e segmentos de mercados atuais e potenciais, levando-se em consideração os pontos fracos e fortes próprios e de seus concorrentes (COBRA, 1997).

É uma atividade orientada pelo longo prazo, em que, tendo em vista a missão e os objetivos da empresa, são desenvolvidos rumos de ação que garantama permanência da empresa através de um portfólio de produtos e serviços competitivos (BATALHA et. al., 2010).

Enquanto que marketing operacional tem suas atividades dirigidas mais para atendimentos e a manutenção dos mercados atuais (ARAUJO, 2010), o marketing operacional enfatiza as atividades de curto prazo, ocupase, também, dos orçamentos de marketing adequados às atividades comerciais da empresa (KOTLER \& ARMSTRONG, 2004).

Para JR\& PETER (2003), as duas abordagens de marketing diferenciam-se pela visão temporal e pelo enfoque adotado. No que se diz respeito ao enfoque, o marketing estratégico preocupa-se com a análise e a prospecção de produtos/mercados e com as estratégias para atacá-las, enquanto o marketing operacional enfoca a execução dos planos 
BARBOSA, F.S.S.P. et al. Marketing na pecuária de corte. PUBVET, Londrina, V. 7, N. 19, Ed. 242, Art. 1602, Outubro, 2013.

estratégicos através do conjunto de elementos do composto mercadológico que a empresa dispõem os quatro Ps (produto, ponto de venda, preço, promoção) ou marketing mix.

\subsection{Estratégias de Marketing}

Uma forma de buscar, segundo KOTLER \& ARMSTRONG (2004), a elaboração do planejamento estratégico é basear-se nos quatro As: análise, adaptação, ativação e avaliação.

\subsubsection{Análise}

Para ARAUJO (2010), a análise do mercado tem por finalidade identificar as forças que nele atuam e de que forma elas interagem com a empresa, de modo a definir claramente os objetivos do empreendimento e as estratégias de produto e de preços.

Em geralos meios para efetuar a análise de mercado são: pesquisas de mercado, efetuadas diretamente com consumidores, de modo a identificar as condições que determinam a localização, a natureza, o tamanho, a direção e a intensidade das forças atuantes nesse mercado e o sistema de informação em marketingcomo um processo contínuo (ARAUJO, 2010).

As análises identificam oportunidades, ameaças e questões estratégicas que afetarão os fatores responsáveis pelo sucesso da empresa ou terão influência estratégica (BATALHAet al., 2010).

\subsubsection{Adaptação}

A adaptação consiste na adequação das linhas de produtos ou serviços da empresa às condições detectadas na análise de mercado, de acordo com as necessidades dos consumidores. Isso significa que toda a linha de produção da empresa volta-se para o atendimento às demandas identificadas, incluindo a definição de tecnologia e processo de produção 
BARBOSA, F.S.S.P. et al. Marketing na pecuária de corte. PUBVET, Londrina, V. 7, N. 19, Ed. 242, Art. 1602, Outubro, 2013.

bem como a seleção de matérias-primas, formas de apresentação do produto, embalagens, distribuição, preços, etc (JR\& PETER, 2003).

\subsubsection{Ativação}

Os produtos ou serviços obtidos, de acordo com as demandas detectadas pela análise, necessitam chegar ao consumidor. Para isso, há a necessidade de um conjunto de medidas para que o produto chegue aos mercados e seja adquirido pelos compradores, no tempo e nas quantidades desejadas, colocando-se em prática as estratégias de distribuição e de comunicação (BATALHA et. al., 2010). A ativação é exatamente esse conjunto de medidas que inclui basicamente a produção propriamente dita, os compostos da comunicação (promoção, vendas, publicidade e relações publicas) e os elementos para escoar os produtos (distribuição, logística de armazenagem e de entregas, vendas).

\subsubsection{Avaliação}

Para BATALHA et. al., (2010) a avaliação é o conjunto de medidas necessárias ao estabelecimentode controles sobre os processos de comercialização, objetivando acompanhar toda distribuição dos produtos e verificar sua receptividade pelos consumidores. Daí a importância,por exemplo, dos serviços de atendimento ao consumidor e de pós venda, de forma a manter uma análise contínua do mercado e do comportamento dos consumidores, podendo, assim, ir além das demandas existentes em determinados momentos e buscar perspectivas de consumo.

\subsection{Planejamento Estratégico}

As estratégias de marketing são definidas pelos quatro Ps: produto, preço, ponto de venda e promoção (ARAúJO, 2010). 
BARBOSA, F.S.S.P. et al. Marketing na pecuária de corte. PUBVET, Londrina, V. 7, N. 19, Ed. 242, Art. 1602, Outubro, 2013.

\subsubsection{Produto}

A definição do produto é obtida depois de desenvolvidas as etapas do marketing estratégico, sobretudo com referência à análise do mercado. E aí são determinadas as principais características físicas e funcionais do produto, a logomarca, a embalagem, as quantidades a serem produzidas, bem como os principais diferenciais em relação aos concorrentes (JR \&PETER, 2003).

O produto pode ser definido, por um conjunto de atributos tangíveis (cor, embalagem, desining) e intangíveis (reputação da marca, prestação de serviços pós-vendas) que pode ser oferecido a um mercado, para sua apreciação e aquisição, uso ou consumo, e que pode satisfazer a um desejo ou uma necessidade (BATALHAet al., 2010). No caso de produtos agroalimentares, alguns aspectos são relevantes, como no caso da carne, que pode ser visto como algo para satisfazer a fome, algo que garante um certo número de nutrientes, ser um produto fácil e prático de se comprar e de consumir com um sabor agradável.

Segundo JR \& PETER (2003), no caso de empreendimentos já existentes, observam-se todos os detalhes do processo de produção, porque podem surgir necessidades de alteração em equipamentos, métodos, rotinas, mão de obra, épocas e escalas. Para empreendimentos projetados, há necessidade de rever todo o projeto antes de sua implantação. O importante é o atendimento da demanda dos consumidores por um produto que busque suprir as expectativas do mercado, em termos de qualidade, comodidade, conveniência e forma de apresentação.

\subsubsection{Preço}

Como nos últimos anos os meios de comunicação evoluíram rapidamente e a oferta de bens e serviços cresceu muito, o consumidor está facilmente bem informado, já tem conhecimento de sua importância no mercado e sabe que está sendo disputado tanto pela indústria como pelo 
BARBOSA, F.S.S.P. et al. Marketing na pecuária de corte. PUBVET, Londrina, V. 7, N. 19, Ed. 242, Art. 1602, Outubro, 2013.

varejo. E para calcular a intensão de lucro, existe uma equação, Quadro 1(ARAUJO, 2010):

$P-C P=L$

Onde:

$\mathrm{CP}=$ Custo de Produção

$\mathrm{P}=$ Preço

$\mathrm{L}=$ Lucro

Quadro 1. Equação para calcular a intenção de lucro.

Fonte: ARAUJO, 2010.

Isso porque o preço já é conhecido e determinado pelo mercado e não mais pelos ofertantes, restando a esses atentar para a variável na qual ainda podem atuar, ou seja, nos custos de produção (JR\& PETER, 2003).

Como os preços máximos são definidos pelo mercado, com base nos preços dos concorrentes e nos preços que os consumidores estão dispostos a pagar, a atenção dos empreendedores concentra-se, predominantemente, nos custos, por que é nestes que os empreendedores ainda têm maior flexibilidade para a atuação (BATALHAet al., 2010).

Com o preço do produto abaixo dos custos totais ou acima dos preços que os consumidores estão dispostos a pagar, o empreendimento não sobrevive. Então, a situação de equilíbrio de preço do produto oscila entre esses dois extremos e, é obvio, quanto maior a diferença entre eles, maior a margem de lucro, levando-se em conta que o preço mínimo tem que cobrir, pelo menos, os custos totais e permitir alguma margem de lucro (KOTLER \& ARMSTRONG, 2004). Quanto menores os custos em relação aos praticados pelos concorrentes, maior a possibilidade de o empreendimento tornar-se competitivo, com preços ao alcance do consumidor, atingindo-se o preço 
BARBOSA, F.S.S.P. et al. Marketing na pecuária de corte. PUBVET, Londrina, V. 7, N. 19, Ed. 242, Art. 1602, Outubro, 2013.

ideal. O preço ideal é aquele que cobre todos os custos, permite margem de lucro e é competitivo em relação aos preços dos concorrentes.

Obviamente, essa racionalidade não abstrai a qualidade de produto, que não pode ser perdida de vista. Por isso é sempre bom lembrar que preço baixo por si só não é o suficiente, sobretudo para se ter a continuidade do empreendimento no mercado a longo prazo (ARAÚJO, 2010).

\subsubsection{Ponto de venda}

O ponto de venda refere-se basicamente á logística de distribuição, de modo que o produto esteja ao alcance do consumidor, no tempo e no local certo, sem perdas de qualidade e com preços competitivos (ROZENFELDet al.,2006).

\subsubsection{Promoção}

Para KOTLER \& ARMSTRONG (2004), promoção refere-se a todo tipo de comunicação necessária para convencer o consumidor a preferir o produto, em relação, a outros, como: propaganda e publicidade; promoção de vendas; malas diretas; internet; merchandising; e vendas.

\subsection{Marketing Agropecuário}

Segundo BATALHA et. al. (2010), de modo geral a produção agropecuária propriamente dita é conduzida mais comumente sem muita referência à mercadologia. O mais comum é produzir por que já há a tradição de fazê-lo, ou por que o vizinho faz, ou porque algum segmento do agronegócio solicitou ou contratou, ou por outras razões, mas não com base em um marketing estratégico, mesmo porque se trata da produção de commodities conduzidas por muitos produtores, geralmente pequenos em relação ao mercado, dispersos espacialmente e pouco organizados. Quando 
BARBOSA, F.S.S.P. et al. Marketing na pecuária de corte. PUBVET, Londrina, V. 7, N. 19, Ed. 242, Art. 1602, Outubro, 2013.

se trata de agronegócio, porém, o marketing ou mercadologia é desenvolvido em termos da empresa e do produto agropecuário.

O marketing rural situa-se entre os produtores de insumos agropecuários e os produtores rurais principalmente (ARAUJO, 2010).

\subsubsection{Marketing em nível de empresa}

De acordo coma posição da empresa na cadeia produtiva, ela tem diferentes tipos de mercados consumidores e, em consequência, diferentes enfoques, tanto para o estabelecimento como para a operacionalização de suas atividades. Assim, as empresas situadas "antes da porteira" terão enfoques diferentes das empresas que se encontram "dentro da porteira" ou "depois da porteira" (JR\& PETER, 2003).

\subsubsection{Empresas "antes da porteira"}

As empresas localizadas "antes da porteira" têm os agropecuaristas como mercado para seus bens e serviços, portanto um mercado, bem definido e bastante previsível. Isso é possível com base em análises de comportamentos anteriores, das previsões de mercado e das políticas de governo e em apoio de dados obtidos com precisão instantânea via satélite, como área cultivada e previsão de safra no local e no mundo e até mesmo de tamanho de rebanho (ARAUJO, 2010).

Segundo KOTLER \& ARMSTRONG (2004), as atitudes desse mercado são previsíveis com certa facilidade, sobretudo quanto as suas necessidades. Os fornecedores de insumos e prestadores de serviços encontram maior dificuldade em definir as tendências mais abrangentes de todo o mercado do agronegócio e em competições com empresas concorrentes dentro do mesmo segmento, do que propriamente com consumidores diretos de seus produtos.

Para ARAUJO (2010), algumas dessas empresas atuam nas duas pontas da cadeia produtiva, de um lado como fornecedoras de insumos ou prestadoras de serviços, e de outro, como compradoras de produtos 
BARBOSA, F.S.S.P. et al. Marketing na pecuária de corte. PUBVET, Londrina, V. 7, N. 19, Ed. 242, Art. 1602, Outubro, 2013.

agropecuários. De modo geral o segmento antes da porteira é formado por grandes empresas que praticam o que há de mais moderno em tecnologia e em mercadologia. São empresas ligadas a engenharia genética, ao desenvolvimento de máquinas, produção de medicamentos, nutrição animal e vegetal e outros segmentos de ponta.

\subsubsection{Empresas "dentro da porteira"}

As empresas consideradas "dentro da porteira" podem apresentar comportamentos muito diferenciados, dependendo dos tipos de produtos, da localização, da produção, do grau de organização dos produtores e da cadeia produtiva. Mas, no geral, a liberdade de atuação é maior no planejamento inicial de seus investimentos (ARAUJO, 2010). Aí sim, há possibilidade de definir um marketing estratégico, definindo o que, quando,quanto e como produzir, estabelecendo, às vezes, até para quem produzir. Porém depois de efetuadas as inversões, os limites para o marketing estratégico ficam reduzidos, devido a rigidez delas, isso quer dizer que uma vez feito um investimento como estrutura e outros, fica difícil mudar o produto produzido.

Para KOTLER \& ARMSTRONG (2004), o que resta, após esse fator limitante, para os produtores é realizar um bom marketing operacional e juntar-se a outros produtores, organizando-se e juntando forças para uma forte negociação, como cooperativas, por exemplo.

Os produtores rurais com alguma liberdade de escolha,como os de grãos, tem a possibilidade de praticar o marketing estratégico antes de definir a intenção sobre o que produzir (ROZENFELDet al., 2006). Para isso a análise de mercado é muito abrangente, envolvendo as preferências dos consumidores, as possibilidades de produção dos concorrentes locais, regionais e mundiais, bem como a logística de distribuição já disponível e as políticas de governo (garantia de preço mínimo, relação com o mercado exterior e outras) 
BARBOSA, F.S.S.P. et al. Marketing na pecuária de corte. PUBVET, Londrina, V. 7, N. 19, Ed. 242, Art. 1602, Outubro, 2013.

O marketing operacional para esses produtores é mais abrangente e a comercialização envolve maiores riscos. Portanto, a organização de produtores a o profissionalismo são mais exigidos(ROZENFELD et al.,2006).

\subsubsection{Empresas "depois da porteira"}

No caso de empresas "depois da porteira", os segmentos econômicos são muito diversificados, como agroindústrias,empresas comerciais e outras (ARAUJO, 2010). Neste caso, já predominam os produtos de marca e já surgem os com certificados de origem. É nesse caso que os quatro As e os quatro Ps do marketing são mais ativamente postos em prática, sobretudo as atividades relacionadas a distribuição, comunicação e avaliação.

Nesses segmentos os produtos deixam de ser commodities e as marcas assumem o papel mais importante na mercadologia, carregando com elas os nomes das empresas. E são exatamente estas que detêm as informações mais atualizadas sobre os desejos de consumo e as expectativas dos consumidores e que, muitas vezes induzem aos consumidores sobre seus próprios desejos (BATALHA et al., 2010). Como geralmente existem grandes empresas nesse segmento elas podem fazer um trabalho de mercadologia e o fazem com muita eficiência, tornando suas marcas mais conhecidas do que elas próprias, ou mesmo transformando suas marcas como sinônimo dos produtos.

\subsection{Cenário Brasileiro no Mercado de Carne Bovina}

No passado,de acordo com GRECELLÉ (2012), a melhor carne era a exportada, hoje, por uma série de fatores, a melhor demanda por carne bovina está aqui mesmo, no Brasil. A renda do brasileiro cresceu, e muito. A carne bovina é a preferência do brasileiro, o consumidor não compra porque ela está mais barata, ele compra porque prefere a carne bovina. A classe média brasileira (classe $C$ ) atualmente é maior do que as classes DE(Figura 1), o que fortalece o crescimento do consumo de carne bovina. 
BARBOSA, F.S.S.P. et al. Marketing na pecuária de corte. PUBVET, Londrina, V. 7, N. 19, Ed. 242, Art. 1602, Outubro, 2013.

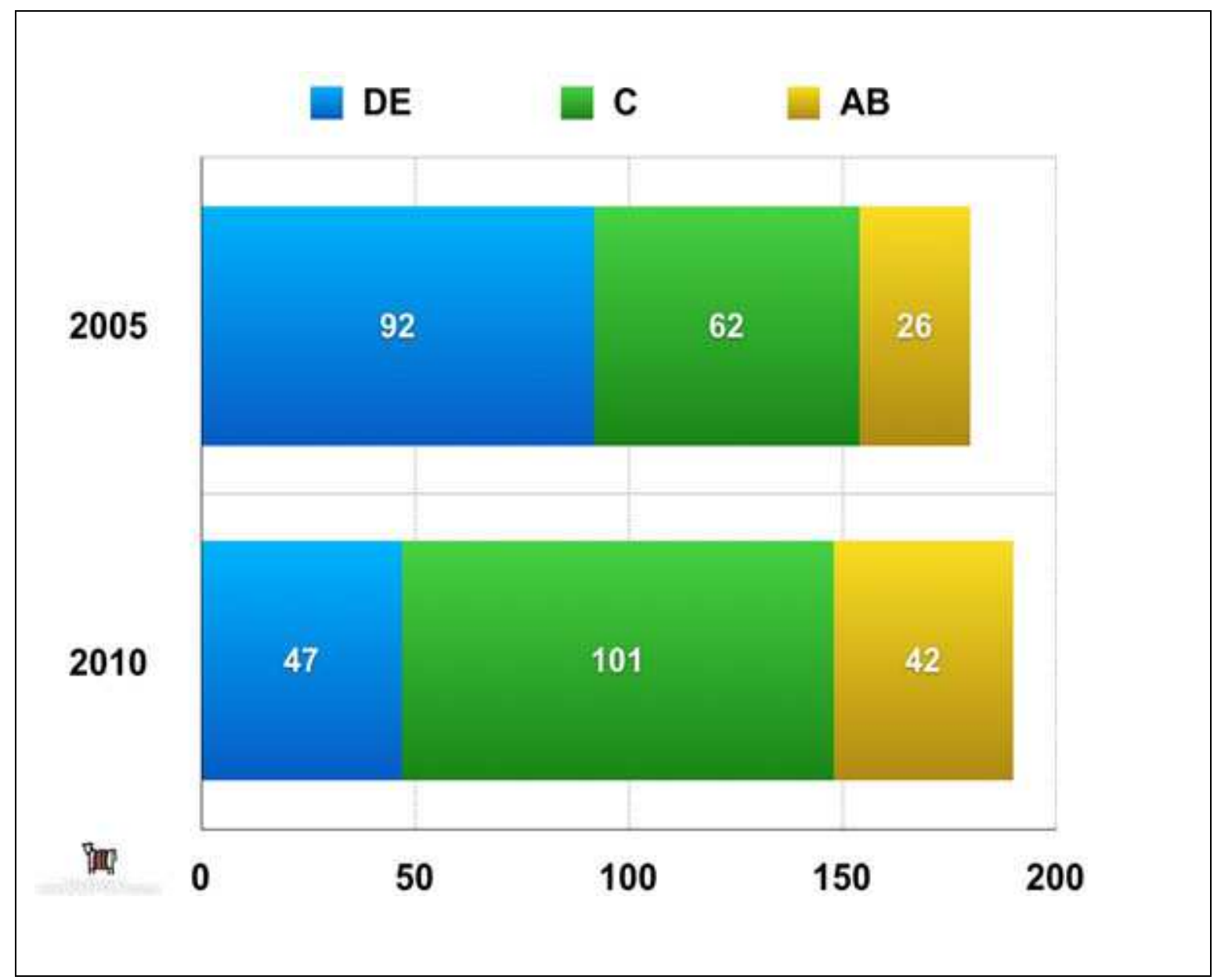

Figura 1. População brasileira, em milhões de pessoas, por classe social, em 2005 e 2010.

Fonte: CRUZ, 2012.

De acordo com CRUZ(2012), nos últimos cinco anos, houve um grande aumento na renda do brasileiro, reduzindo a pobreza e aumentando o número de pessoas na classe média e alta, gerando um maior consumo de carne e de demanda por carnes especiais.

Com essa mudança o Brasil possui um perfil de distribuição de renda cada vez mais parecido com países ricos (onde a classe média é maior que a classe pobre). Essa grande migração das classes DE para C, e também da C para $A B$, significa um maior consumo, em quantidade e qualidade, de tudo, inclusive carne bovina. É por isso que o país já tem mais de uma dezena de marcas de carnes atacando esses nichos de mercado(GRECELLÉ, 2012).

Ainda segundo GRECELLÉ(2012),produzir carne bovina é caro, difícil e demorado. No Brasil, a produção é muito eficiente, mas no mundo tudo isso 
BARBOSA, F.S.S.P. et al. Marketing na pecuária de corte. PUBVET, Londrina, V. 7, N. 19, Ed. 242, Art. 1602, Outubro, 2013.

é um assunto cada vez mais importante, porque os principais países produtores terão dificuldades em aumentar a oferta, sendo que a demanda mundial não para de crescer.

Segundo GARCIA (2012), o Brasil será cada vez mais importante como país produtor de carne bovina, devido ao elevado potencial produtivo e aos problemas de oferta de seus concorrentes, como os EUA, Europa, Argentina e Austrália, que não conseguem crescer a produção. Aqui na América do Sul, além dos problemas políticos na Argentina, o Uruguai passa por uma redução de rebanho e o Paraguai luta contra a aftosa e reconquista da confiança e acesso no mercado internacional.

O aumento de demanda mundial por carne bovina virá de países em desenvolvimento, onde o Brasil é um ótimo exemplo, por produzir carne de altíssima qualidade e vender pelo mesmo preço que a carne mais cara dos EUA. O produto de luxo está globalizado e o Brasil tem nichos e segmentos de mercado que pagam tão bem quanto os melhores dos EUA e Europa (CAVALCANTI, 2012).

Esse cenário é muito positivo para a pecuária de corte, sendo necessário atenção e foco, dos produtores, em duas áreas: gestão eficiente para manter margens num cenário de preços altos e foco na qualidade, pois a demanda por carne de qualidade e cara será maior do que a demanda por carne de baixa qualidade e barata (CRUZ, 2012).

O consumo mundial de carne bovina crescerá $14,5 \%$ de 2010 a 2019, um incremento de 9,3 milhões de toneladas, necessitando de um aumento na produtividade para atender essa demanda, pois a área ocupada pela bovinocultura não irá crescer, em consequência do avanço da agricultura em áreas de pastagens e pela enorme dificuldade em se abrir novas áreas (GARCIA, 2012).

\subsection{Mercado Mundial da Carne Bovina}

As previsões de médio e longo prazo para o mercado mundial de carne bovina são muito favoráveis para o Brasil, o crescimento virá dos 
BARBOSA, F.S.S.P. et al. Marketing na pecuária de corte. PUBVET, Londrina, V. 7, N. 19, Ed. 242, Art. 1602, Outubro, 2013.

países emergentes. Os países desenvolvidos devem crescer muito pouco nos próximos anos. Nos EUA e Reino Unido, a crise já chegou à economia real, com claros sinais de recessão. A China revisou sua previsão de crescimento em 2008, de 10,1\% para 9,0\%, um número ainda bastante expressivo (NEVES et al., 2010).

Os dois grandes aumentos da produção de carne bovina para os próximos dez anos devem vir da China e do Brasil. A produção chinesa é quase toda voltada para o mercado interno, mas o problema na China é a falta de água, que pode impedir esse crescimento (CAVALCANTI, 2012).

Uma previsão do FMI(Figura 2), indica um crescimento do PIB mundial na ordem de 3,9\% em 2008, 3\% em 2009, 4,2\% em 2010,4,8\% em 2011. Ou seja, depois de alguns anos de forte crescimento, em 2008 e 2009 o mundo cresce menos, iniciando uma recuperação entre 2009-2010 (CAVALCANTI, 2012).

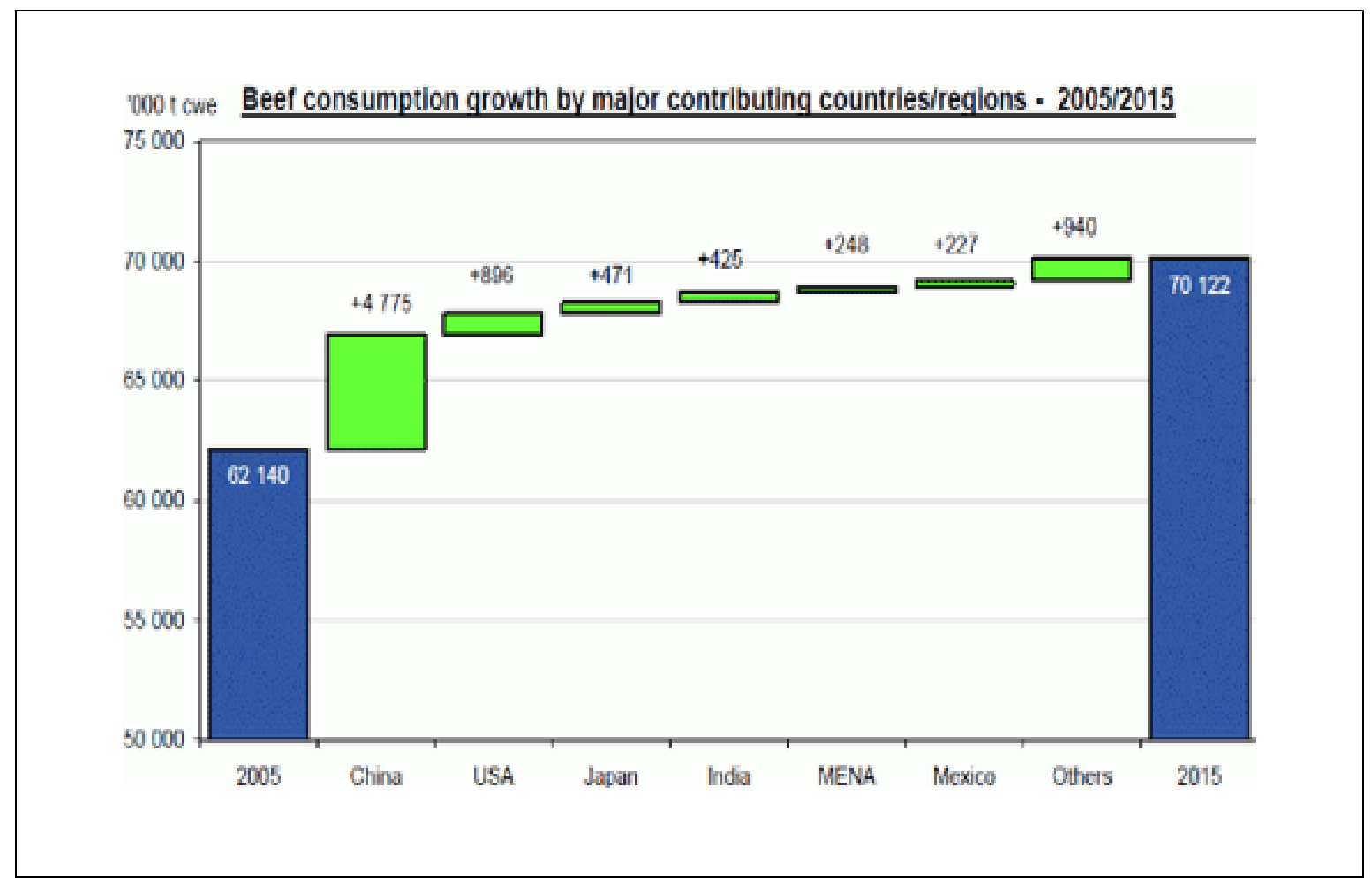

Figura 2. Países que mais contribuíram para o crescimento no consumo de carne - 2005/2015

Fonte: CAVALCANTI, 2012. 
BARBOSA, F.S.S.P. et al. Marketing na pecuária de corte. PUBVET, Londrina, V. 7, N. 19, Ed. 242, Art. 1602, Outubro, 2013.

A demanda mundial por carnes no mundo cresce graças ao aumento da população, da renda per capita e urbanização (ou seja, mais pessoas vivendo em cidades e menos no campo)esperando-se um maior consumo em países emergentes, em crescimento e com aumento do percentual da população que vive nas cidades (ALVIN etal., 2007). Sendo a China o país que melhor representa as mudanças causadas por essas três grandes tendências.

O Brasil, em 2008, concentrou muito mais suas exportações para países em desenvolvimento, em especial para países exportadores de petróleo. A impossibilidade de exportar grandes volumes para $U E$, devido a problemas com rastreabilidade, ajudou nessa concentração (CAVALCANTI, 2008).

Mas, para CRUZ(2012), as importações também devem crescer nos EUA e UE, graças à limitação de oferta interna e demanda constante. Os EUA é o segundo país (depois da China) que terá o maior aumento absoluto nas importações, considerado hoje um dos maiores importadores de carne bovina do mundo, mercado que o Brasil ainda não atinge, devido a impasse na área sanitária.

A UE também terá aumento nas importações (e redução das exportações). O custo de produção na Europa cresce, abrindo cada vez mais espaço para outros países, como Argentina, Uruguai, Paraguai e principalmente Brasil. A UE, que há cerca de dez anos exportava um milhão de toneladas por ano, deve passar em poucos anos para importador de um milhão de toneladas, passando de concorrente do Brasil nas exportações para importador (GARCIA, 2012).

Para atingir mercados em países desenvolvidos, será preciso se adequar às regras e normas de cada país.A meta da ABIEC(Associação Brasileira das Indústrias Exportadoras de Carne) é começar a exportar para os EUA, tendo como previsão de receita com as exportações totais do Brasil para 2013, US $\$ 13$ bilhões, quase três vezes o valor atual (ABIEC, 2012). 
BARBOSA, F.S.S.P. et al. Marketing na pecuária de corte. PUBVET, Londrina, V. 7, N. 19, Ed. 242, Art. 1602, Outubro, 2013.

\subsection{Os Avanços na Cadeia Brasileira de Corte}

Segundo CAVALCANTI(2012), o avanço da cadeia de carne bovina no Brasil está na conquista de mercados emergentes como Ásia, Oriente Médio e Norte da África, que devem incrementar suas compras em $5 \%$ neste ano, para 8,2 milhões de toneladas. A crise econômica que teve início nos EUA e depois chegou à Europa ajudou a acelerar a mudança do mapa do comércio mundial de alimentos. Se em 1965 os países em desenvolvimento representaram 15,4\% das importações mundiais de carnes, em 2010 essa fatia chegou a $55,4 \%$.

As perspectivas para o segmento no Brasil não são menos otimistas, com a ascensão econômica da classe C, que representa $54 \%$ da população brasileira. Com renda mensal familiar média de $R \$ 2.900$, o perfil desse consumidor mudou rapidamente, em especial na área de alimentação, com um aumento de $4,2 \%$ das compras de carne bovina de primeira, em especial filé mignon e picanha (CRUZ, 2012).

A cadeia movimentou US $\$ 167,8$ bilhões em 2010 , somando-se todas as vendas realizadas - como insumos utilizados nas fazendas, cercas e medicamentos e animais vendidos aos frigoríficos - até chegar às carnes e subprodutos comercializados pelas indústrias. É uma atividade que gera sete milhões de empregos, US $\$ 16,5$ bilhões de impostos agregados e faturamento de US $\$ 42$ bilhões para os frigoríficos, dos quais $89 \%$ foram contabilizados no mercado interno e $11 \%$ com exportações(NEVES et. al.,2010).

Mesmo que o principal mercado da indústria ainda seja o interno, que absorve $91 \%$ da produção nacional estimada em 9,17 milhões de toneladas - o segmento precisa intensificar o comércio Brasil afora, não apenas em emergentes tradicionais como Rússia e China. Há forte ascensão no Egito, Irã, Malásia, Filipinas, entre outro (JP, 2012). O Brasil é atualmente o principal exportador de carne bovina do mundo, com $20 \%$ do 
BARBOSA, F.S.S.P. et al. Marketing na pecuária de corte. PUBVET, Londrina, V. 7, N. 19, Ed. 242, Art. 1602, Outubro, 2013.

mercado internacional e vendas que geraram faturamento de US $\$ 3,9$ bilhões, resultado do comércio de 953 mil toneladas.

No entanto, para que ambos os mercados - interno e externo - não corram o risco de serem mal atendidos, estudos projetam aumento na produção em 2017 para 14,9 milhões de toneladas, com excedente de cerca de 5,3 milhões de toneladas. Muitas razões podem ser atribuídas para este crescimento, incluindo crédito rural para a renovação dos rebanhos e melhoria na genética e nas pastagens que vão aumentar o tamanho das criações e permitir maior oferta de animais prontos para o abate. Alguns frigoríficos têm feito parceria com produtores para aumentar o número de animais confinados e mantê-los prontos para o abate durante todo o ano (JP, 2012).

O estudo sobre a cadeia produtiva não despreza os gargalos da pecuária nacional. Um deles é a queda nas exportações nos últimos cinco anos, especialmente para a União Europeia, que consome 8,19 milhões de toneladas por ano. A partir de 2008, os países do bloco impuseram medidas sanitárias mais rígidas para o Brasil. Por outro lado, os Estados Unidos apesar de serem os principais compradores de carne bovina do mundo, não importam carne in natura brasileira. Por sua posição de exportador, o Brasil será sempre alvo de medidas protecionistas provenientes de países que não contam com a mesma competitividade agrícola. Entretanto, não se pode ignorar o fato de que países ricos reduziram o consumo nos últimos anos em decorrência de uma crise financeira que diminuiu taxas de crescimento econômico e teve reflexos importantes sobre o poder de compra dos consumidores nos EUA e na União Europeia (JBS, 2012).

Mas, o Brasil precisa brigar por estes mercados, além de fortalecer os negócios com os países emergentes, pois os EUA possuem mais de 300 milhões de habitantes, sendo o segundo maior importador de carne bovina do mundo, ficando atrás apenas da União Europeia (ABIEC, 2012).

Essa disputa de mercadoesbarra na falta de aptidão do governo em negociar melhores tarifas, já que o Brasil tem um peso muito maior no 
BARBOSA, F.S.S.P. et al. Marketing na pecuária de corte. PUBVET, Londrina, V. 7, N. 19, Ed. 242, Art. 1602, Outubro, 2013.

cenário internacional do que há dez anos. Isto acomete o caso da União Europeia, que há três anos estabeleceu uma série de novas exigências para vendas de cortes nobres dentro da cota Hilton - que tem preços mais atraentes no mercado internacional -, o que fez com que o país conseguisse cumprir menos de $10 \%$ do volume de dez mil toneladas a que tinha direito entre os anos de 2009 e 2010 (NEVES et al., 2010).

Outro problema está no fato da carne ainda ser comercializada em grande volume como commodity, sem diferenciação. Cada vez mais, os consumidores querem carne segura, produzida com respeito ao meio ambiente, além de buscar cortes que propiciem preparo rápido e fácil. Um exemplo é o programa de marketing "BrazilianBeef", da ABIEC, como uma ação que pode fortalecer a imagem da carne bovina nacional no exterior. No mesmo sentido vai uma linha de carne orgânica criada pela JBS, com o intuito de valorizar boas práticas agropecuárias com produtos finais sem agrotóxicos ou aditivos (ABIEC, 2012).

Estudos apontam que o aumento do consumo mundial será suprido por Brasil e Índia - que deve aumentar em 7\% sua produção, para 3,3 milhões de toneladas em 2012 -, que têm condições de se consolidarem como fornecedores regulares de carne bovina para o mundo. "A quantidade de animais vem diminuindo nos países com os maiores rebanhos e 0 brasileiro só vem aumentando". Entre os anos de 2000 e 2010, houve incremento de 28,3\%, para 209,5 milhões de cabeças. Nos EUA, a redução foi de 5,3\% (plantel de 93,8 milhões de animais) e na União Europeia foi de $9,6 \%$ (atuais 88,3 milhões de cabeças). Por outro lado, a Austrália crescerá para níveis quase recordes (1,38 milhão de toneladas), baseada em maiores ofertas e atendimento a mercados rentáveis como Japão, Coreia do Sul e EUA entre outros. Nos próximos dez anos os gastos com alimentação na China devem subir $50 \%$ e na Índia $78 \%$, o que possivelmente influenciará no ritmo de aumento do consumo de carne bovina. Esses mercados permitirão ao Brasil manter sua posição de principal exportador no mundo (GRECELLÉ, 2012). 
BARBOSA, F.S.S.P. et al. Marketing na pecuária de corte. PUBVET, Londrina, V. 7, N. 19, Ed. 242, Art. 1602, Outubro, 2013.

\subsection{Marketing na Pecuária de Corte Brasileira}

Aforma como o consumidor enxerga um determinado produto é fator decisivo no ato da compra. O hábito de consumo de uma pessoa está intimamente ligada as suas preferências e percepções sobre o item a ser adquirido. Preço, características e apresentação são acompanhadas por outros itens que dizem respeito à maneira como o consumidor entende um determinado produto, dentro de uma visão sistêmica ecomplexa. Sendo exatamente essa visão de como o consumidor enxerga a carne bovina brasileira que deve ser trabalhada (GARCIA, 2012).

Segundo GRECELLÉ (2012), o mercado internacional e o consumidor interno são carentes de informações sobre o ambiente de produção da carne bovina brasileira e esperar que o consumidor se informe sobre estes aspectos leva tempo e dinheiro.

Entende-se que é necessário existir duas frentes de atuação, para melhorar esse quadro. Uma que cabe ao produtor, à indústria e ao varejo, a produção do alimento dentro do padrão desejado. Outra que deve ficar sob a responsabilidade daqueles que pensam a pecuária e representam os diferentes elos da cadeia produtiva da carne bovina, comunicando os produtos deste segmento (CRUZ, 2012).

Existe uma tendência de pensar apenas em publicidade de marcas, e não é isso o necessário. É preciso vender um conceito, uma ideia, comunicar de forma inteligente as verdades. Necessita mostrar ao consumidor interno e ao mundo que o Brasil produz carne de maneira bem menos devastadora do que é vendido maliciosamente. $O$ consumidor precisa entender que por trás da carne ofertada diariamente nas gôndolas do varejo existe um homem do campo, um trabalhador, que acorda cedo e trabalha duro. Que luta contra as adversidades do clima, da economia, do mercado, da política e de todos os fatores que condicionam a sua atividade (CAVALCANTI, 2012).

É necessário que a população urbana compreenda o meio rural, adotando o homem do campo, consumindo os seus produtos, sem nenhum tipo de receio.Por isso é que se insiste na necessidade de comunicar. $O$ 
BARBOSA, F.S.S.P. et al. Marketing na pecuária de corte. PUBVET, Londrina, V. 7, N. 19, Ed. 242, Art. 1602, Outubro, 2013.

consumidor não precisa entender o sistema de produção minuciosamente, mas ele precisa estar mais bem informado sobre os aspectos gerais, para que assim, tenha competência para decidir pela compra dos produtos (GARCIA, 2012).

Recentemente, durante o nono congresso da Associação Brasileira do Agronegócio (ABAG) houve uma sinalização daquilo que vem sendo apontado como uma das grandes deficiências do agro brasileiro. Ficou registrado o desafio/intenção de uma grande mobilização nacional entorno dessa questão. A promoção da agricultura e da pecuária nacional é pra ontem, e tem de ser feita com profissionalismo e isenção, não podendo ter ruídos e interesses individuais de entidades, indústrias ou associações, deve ser uma campanha de todos, pelo bem coletivo (LOVATELLI, 2010).

A carne bovina é vista pelos consumidores como um produto especial,e em momentos especiais de nossas vidas, pedimos um bom pedaço de carne para comemorar. Nenhuma outra proteína animal é tão escolhida para momentos marcantes. Há uma relação muito forte, já estabelecida em muitos lugares do mundo, entre carne bovina e ocasiões comemorativas. Essa é uma das maiores forças da carne, e pode (precisa) ser mais explorada (PESSINA, 2012).

Mais do que tornar cada produto melhor, o que pode ser feito utilizando as melhores práticas de produção e industrialização, o vinho, azeite e café, procuram também valorizar o que há de especial, de notável, diferente em cada região e variedade. Isso gera variedade e escolha e é uma forma muito interessante de educar o consumidor a entender que há mais (CAVALCANTI, 2008).

As pessoas, no Brasil e no mundo, consomem opções especiais desses produtos, pois têm mais renda, querem conhecer e degustar mais sabores. Outro fenômeno é o aumento das refeições fora de casa (típico de aumento de renda) e também o maior interesse por gastronomia. E carne especial não é um produto apenas para ricos, mas um produto para ocasiões especiais. Quanto maior a renda, maior a frequência de consumo, mas 
BARBOSA, F.S.S.P. et al. Marketing na pecuária de corte. PUBVET, Londrina, V. 7, N. 19, Ed. 242, Art. 1602, Outubro, 2013.

muitas faixas de renda podem consumir produtos especiais, mesmo que não seja no dia-a-dia, aumentando ainda mais o potencial de consumo (JBS, 2012).

No caso da carne bovina há três vertentes possíveis de diferenciação. A primeira é a região, havendo lugares que a produção é mais propícia, e isso pode ser muito bem explorado. Como exemplo o que acontece desde o pampa gaúcho, até o vale do Araguaia; outra vertente são as raças especializadas, explorando o que cada uma tem de melhor, de mais peculiar, único e diferente; e a última oportunidade são os sistemas de produçãouma vez que o gado terminado em confinamento ou com uso de grãos mais intenso (como o semi-confinamento) geralmente tem idade mais jovem e maior acabamento de gordura, sendo duas exigências para maciez. Por outro lado, há uma tendência mundial em busca de alimentos naturais e a carne a pasto se insere perfeitamente nessa demanda (NEVES et al., 2010).

Há espaço para cada tipo de consumidor e de produto, não adianta bater de frente, mas cada um deve buscar seu segmento de mercado. Os consumidores que procuram uma carne mais magra (por questões de saúde e dieta) não são os mesmos que procuram uma carne especial para churrasco com mais gordura por exemplo. Ou pelo menos a ocasião de consumo não será a mesma (GARCIA, 2012). Com isso o mercado não se afunila e sim se expande (GRECELLÉ, 2012).

Para CAVALCANTI(2012), criar formas de ensinar, educar o consumidor de forma inteligente sobre todas essas possibilidades é muito promissor e ainda tem um efeito positivo no combate aos ativistas anticarne que adoram aproveitar o desconhecimento e espalhar sua versão dos fatos.

Outro ponto positivo da busca pela valorização da carne de qualidade é a melhora no relacionamento entre os frigoríficos e os fornecedores, tornando-se ainda mais importante nos tempos de baixa oferta.Também é importante reforçar que o principal motivo que as pessoas comem carne bovina não é apenas o preço baixo ou porque os médicos recomendam para 
BARBOSA, F.S.S.P. et al. Marketing na pecuária de corte. PUBVET, Londrina, V. 7, N. 19, Ed. 242, Art. 1602, Outubro, 2013.

uma dieta saudável, pelos atributos nutricionais, e sim porque a consideram deliciosa (CRUZ, 2012).

\subsection{Bom exemplo: Marketing Australiano}

Segundo GARCIA (2012), a Austrália tem o MLA (Meat\&LivestockAustralia) órgão não político, não governamental, coordenado por um conselho composto por dez experts em áreas correlatas e que nesta composição tem dois representantes de gado bovino, um representante de ovinos e um representante dos frigoríficos. O conselho é eleito pelo voto dos 45.000 associados e os próprios associados se candidatam aos cargos. A função do MLA é tratar do marketing e pesquisas da carne australiana com o objetivo de aumentar a produção e vendas, aumentar a lucratividade e a demanda. A entidade conta com 250 pessoas a seu serviço e têm escritórios nos EUA, Japão, Oriente Médio, Coréia, Europa e Ásia.

Com um recolhimento de $\$ 5,00$ (cinco dólares australianos, equivalente a mais ou menos $\mathrm{R} \$ 10,00$ ) por cabeça comercializada, e quantia equivalente vinda do governo, pelo recolhimento de impostos dos frigoríficos, a entidade conta com uma verba anual em torno de US $\$ 100$ milhões de dólares americanos(MEAT \& LIVESTOCK AUSTRALIA, 2012).

Alicerçada em quatro pilares: aumento de produtividade; integridade, sustentabilidade e meio ambiente; garantia de acesso a mercados; e aumento da demanda interna, o MLA faz pesquisas de novos mercados e divulgação do valor nutricional da carne como alimento importante numa dieta saudável. Também pesquisa possibilidades de robotização da indústria frigorífica, prospecta e fomenta a exportação de gado em pé, faz pesquisas quanto ao manejo, alternativas forrageiras e nutricionais e ainda faz pequenos dias de campo para divulgar tudo aos associados através do MeatProfitable Day (Dia da Carne Lucrativa). E ainda ensina os açougueiros a fazer os cortes e comercializar a carne que tem $30 \%$ da venda realizada por estes no mercado interno. Esse é um canal de 
BARBOSA, F.S.S.P. et al. Marketing na pecuária de corte. PUBVET, Londrina, V. 7, N. 19, Ed. 242, Art. 1602, Outubro, 2013.

vendas em expansão, tomando espaço dos supermercados que detêm os 70\% restantes. Um "MLA equivalente BRASILEIRO" poderia alavancar com um rebanho de 200 milhões de cabeças (MEAT \& LIVESTOCK AUSTRALIA, 2012).

Além do MLA, os produtores são um grande diferencial, devido a uma escassez absoluta de trabalhadores, com uma população de somente 23 milhões de pessoas e um valor muito alto do custo do dia de serviço. São US $\$ 200,00$ por dia trabalhado e após $70 \%$ do tempo anual dedicado para uma empresa ainda incide $20 \%$ de encargos que o trabalhador escolhe como quer que seja aplicado o seu recurso. Com isso as famílias australianas gerenciam, elas mesmas, suas fazendas e trabalham duro no dia-a-dia do manejo (THE CATTLE SITE, 2007).

Um bom exemplo de marketing é o que ocorre, a cada três anos, na feira australiana de Rockhampton, onde é realizada uma apresentação teatral ao ar livre, com em torno de 100 pessoas, com a participação de crianças e jovens. Sendo o mais importante à participação das crianças, jovens, adultos e todos os envolvidos, criando novas gerações e com orgulho de representarem as suas famílias e o seu país em uma atividade de grande importância econômica para a sociedade como um todo (BEEF CENTRAL, 2012).

\section{CONSIDERAÇÕES FINAIS}

Todo o processo mercadológico depende de um marketing adequado, direcionado ao mercado consumidor desejado. O produto não parte da empresa para o cliente e sim, do cliente para a empresa, pois uma empresa não deve produzir algo sem antes saber aonde irá vender, e quem escolhe o produto a ser consumido é o consumidor.

Na pecuária de corte não há diferença, qualquer produtor ou órgão envolvido deve escolher bem como produzir e como fazer com que esse produto chegue até o consumidor. Sempre lembrando que o lucro está relacionado ao custo de produção e ao preço de venda, quanto menor for 0 
BARBOSA, F.S.S.P. et al. Marketing na pecuária de corte. PUBVET, Londrina, V. 7, N. 19, Ed. 242, Art. 1602, Outubro, 2013.

custo maior será o lucro, não esquecendoa qualidade, pois é ela quem vai garantir a fidelidade do cliente.

O Brasil é um dos principais países produtores de carne no mundo, isto tudo sem um marketing adequado. Com a adoção de um conceito mercadológico sólido para a área, os ganhos seriam imensos para o país, a população e para o consumidor.

\section{REFERÊNCIAS BIBLIOGRÁFICAS}

ABIEC. Cadeia da carne bovina. Disponível em: http://www.beefpoint.com.br/cadeiaprodutiva/giro-do-boi/abiec-cadeia-da-carne-bovina-brasileira-deve-mirar-mercadosemergentes-diz-estudo/. Acessado em:1 de maio de 2012.

ALVIM, C. et al. O mercado da carne bovina no Brasil. Revista Cientifica de Medicina Veterinária, 2007.ISSN 1679-7353. Ano

V. n. 09.

ARAÚJO, M. J. Fundamentos de agronegócios.3.ed. São Paulo: Atlas, 2010. 159 p.

BATALHA, M. O. et al.Gestão agroindustrial.3.ed. São Paulo: Atlas, 2010. 770 p.

BEFF CENTRAL.Handshakes creating international export linkages.Disponível em: http://www.beefcentral.com/beef-2012/article/1640.Acessado em: 19 de maio de 2012.

CAVALCANTI, M. R. 2012 o ano do marketing no mercado interno. Disponível em: http://www.beefpoint.com.br/cadeia-produtiva/editorial/2012-o-ano-do-marketing-dacarne-no-mercado-interno-75153/. Acessado em: 20 de maio de 2012.

CAVALCANTI, M. R. Mercado mundial da carne bovina: Perspectivas para o Brasil. Disponível em: http://www.beefpoint.com.br/cadeia-produtiva/editorial/mercado-mundialda-carne-bovina-perspectivas-para-o-brasil-49274/. Acessado em: 2 de maio de 2012.

CAVALCANTI, M. R. Qual a melhor forma de vender carne no momento atual do mercado. Disponível em: http://www.beefpoint.com.br/cadeia-produtiva/editorial/qual-amelhor-forma-de-vender-carne-no-momento-atual-de-mercado-69213/. Acessado em: 30 de maio de 2012.

COBRA, M. H. N. Marketing Básico: perspectiva brasileira. 4. Ed. SãoPaulo: Atlas, 1997. 552 p.

CRUZ, C. Produtos premium e perspectivas do mercado brasileiro. Disponível em: http://www.beefpoint.com.br/cadeia-produtiva/entrevistas/celso-cruz-diretor-de-supplychain-do-mcdonalds-fala-sobre-hamburguer-angus-produtos-premium-e-perspectivas-domercado-brasileiro/. Acessado em: 10 de março de 2012.

GARCIA, M. O "segredo" australiano. Disponível em: http://www.beefpoint.com.br/cadeia-produtiva/espaco-aberto/o-segredo-australiano/. Acessado em: 19 de maio de 2012. 
BARBOSA, F.S.S.P. et al. Marketing na pecuária de corte. PUBVET, Londrina, V. 7, N. 19, Ed. 242, Art. 1602, Outubro, 2013.

GRECELLÉ, R. A. Marketing da carne: Pela divulgação profissional da pecuária brasileira. Disponível em: http://www.beefpoint.com.br/mypoint/9271/marketing-dacarne-pela-divulgacao-profissional-da-pecuaria-brasileira/. Acessado em: 28 de maio de 2012.

JP, Q. M. Austrália: 0 bom exemplo do marketing da carne. Disponível em: http://www.portaldoagronegocio.com.br/conteudo.php?id=23711. Acessado em: 10 de maio de 2012.

JBS. JBS: estratégia de expansão. Disponível em: http://www.beefpoint.com.br/cadeiaprodutiva/giro-do-boi/estrategia-de-expansao-do-jbs-e-vista-com-cautela/.Acessado em: 1 de junho de 2012.

JR., G. C.; PETER, J. P. Marketing: Criando Valor Para os Clientes. 2.ed. Saraiva, 2003. $626 p$.

KOTLER, P; ARMSTRONG, G. Princípios de Marketing.9.ed. São Paulo: Prentice Hall, 2004. 593p.

LOVATELII, C. Propostas da ABAG para o cenário do agronegócio. In: Anais IX congresso do agronegócio brasileiro, 2010, São Paulo. Anais Associação Brasileira do Agronegócio, 42 p.

MEAT \& LIVESTOCK AUSTRALIA. MLA appoints Global Marketing General Manager. Disponível em: http://www.mla.com.au/about-the-red-meat-industry/about-mla/news-andmedia/media-releases/mla-appoints-global-marketing-general-manager. Acessado em: 22 de fevereiro de 2012.

MEAT \& LIVESTOCK AUSTRALIA. Marketing redmeat. Disponível em: http://www.mla.com.au/Marketing-red-meat. Acessado em: 22 de maio de 2012.

NEVES, M. F. et al.Marketing da Carne Bovina com Vicão de Redes de Empresas ('Networks').Revista semestral editada pela universidade Federal de Lavras, v.4, n.2,2010, p.73-85.

PESSINA, A. Cadeia da carne bovina e seus desafios. Disponível: http://www.beefpoint.com.br/mypoint/12771/cadeia-da-carne-bovina-e-suas-desafios/.

Acessado em: 1 de maio de 2012.

RANK BRASIL. Maior rebanho bovino comercial. Disponível em: http://www.rankbrasil.com.br/Recordes/Materias/OLu8/Maior_Rebanho_Bovino_Comercial. Acessado em: 30 de maio de 2012.

ROZENFELD, $H$. et al.Gestão de desenvolvimento de produtos: Uma referência para a melhoria do processo. São Paulo: Saraiva, 2006. 542 p.

THE CATLLE SITE.Alternative marketing arrangements benefit livestock producers, meat industries, consumers. Disponível em: http://www.thecattlesite.com/news/15313/alternative-marketing-arrangements-benefitlivestock-producers-meat-industries-consumers. Acessado em: 1 de junho de 2012. 